
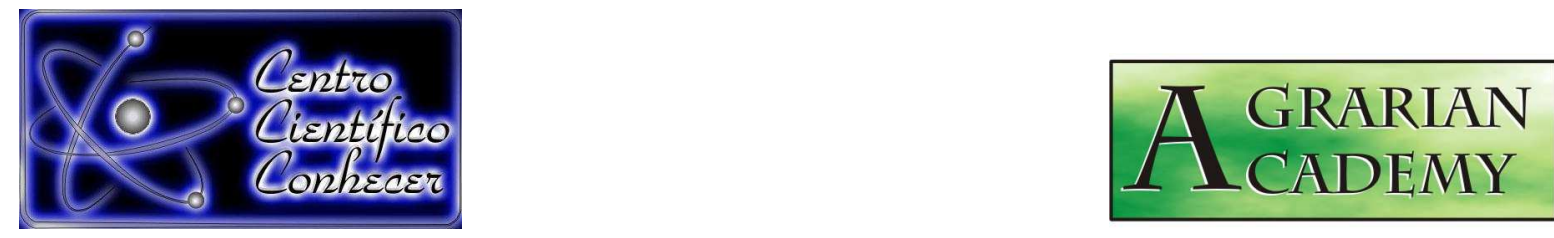

\title{
AÇÃO ALELOPÁTICA DE FOLHAS SECAS DE UMBU, EM PROCESSO DE DECOMPOSIÇÃO, SOBRE O POTENCIAL FISIOLÓGICO DE SEMENTES DE FEIJÃO CAUPI
}

\author{
Joyce Naiara da Silva ${ }^{1}$, Monalisa Alves Diniz da Silva Camargo Pinto ${ }^{2}$ \\ 1. Acadêmica em Agronomia da Unidade Acadêmica de Serra \\ Talhada/Universidade Federal Rural de Pernambuco (UAST/UFRPE) \\ (joicenaiara@hotmail.com) \\ 2. Professora Doutora Associado I da Unidade Acadêmica de Serra \\ Talhada/Universidade Federal Rural de Pernambuco (UAST/UFRPE) - Serra \\ Talhada, PE, Brasil.
}

Recebido em: 30/11/2017 - Aprovado em: 15/12/2017 - Publicado em: 31/12/2017

DOI: 10.18677/Agrarian Academy 2017b2

\begin{abstract}
RESUMO
Objetivou-se identificar uma possível influência alelopática das folhas secas, em processo de decomposição, da espécie nativa da região Nordeste do Brasil Spondias tuberosa Arr. Cam. no desenvolvimento inicial de plântulas de feijão caupi. As folhas da espécie florestal foram coletadas pela manhã, em seguida secas a 60 -C por 24 horas em estufa, estas foram esmagadas manualmente e misturadas com areia, adotando-se a seguinte proporção de areia e folhas secas: 1:0;1:1/2; 1:1 e 1:2 (v:v). As folhas presentes em cada mistura ficaram decompondo por um período de zero; 15; 30; 45 e 60 dias para posterior semeadura das sementes de feijão caupi. As variáveis analisadas foram porcentagem de emergência (PE), índice de velocidade de emergência (IVE), tempo médio de emergência (TME), comprimento da parte aérea (CPA) e do sistema radicular (CSR), massa seca da parte aérea (MSPA), do sistema radicular (MSSR) e total (MST). O delineamento utilizado foi o inteiramente casualizado em esquema fatorial $4 \times 5$. Quando avaliados os parâmetros de germinação observou-se que a utilização de folhas secas de umbu causou efeitos negativos sobre as plântulas de feijão. Para os parâmetros de crescimento, quando utilizadas folhas de umbu as plântulas de feijão caupi tiveram suas partes aéreas mais afetadas, enquanto que as raízes se mostraram menos sensíveis. Diante disso, o cultivo de feijão caupi como parte integrante de um sistema agroflorestal em que exista o umbuzeiro não é recomendado.
\end{abstract}

PALAVRAS-CHAVE: Consórcio, espécie nativa, germinação. 


\title{
ALELOPATIC ACTION OF DRIED LEAVES OF UMBU, IN THE DECOMPOSITION PROCESS, ON THE PHYSIOLOGICAL POTENTIAL OF BEANS SEED CAUPI.
}

\begin{abstract}
The objective of this study was to identify a possible allelopathic influence of the dry leaves, in the process of decomposition, of the native species of the Northeast region of Brazil Spondias tuberosa Arr. Cam. On the initial development of cowpea seedlings. The leaves of the forest species were collected in the morning, then dried at $60 \stackrel{\circ}{\circ}$ for 24 hours in a greenhouse, they were manually crushed and mixed with sand, using the following proportion of sand and dry leaves: $1: 0 ; 1: 1 / 2 ; 1: 1$ and $1: 2$ (v: v). The leaves present in each mixture were decomposed for a period of zero; 15 ; 30; 45 and 60 days for subsequent sowing of cowpea beans. The variables analyzed were percentage of emergence (PE), emergency speed index (IVE), mean time of emergency (EMS), aerial part length (CPA) and root system (CSR) ), root system (MSSR) and total (MST). The design was completely randomized in factorial scheme $4 \times 5$. When germination parameters were evaluated, the use of dried leaves of umbu caused negative effects on bean seedlings. For the growth parameters, when using umbu leaves the cowpea seedlings had their aerial parts more affected, while the roots were less sensitive. Therefore, the cultivation of cowpea as an integral part of an agroforestry system in which there is umbuzeiro is not recommended.
\end{abstract}

KEYWORDS: Consortium, native species, germination

\section{INTRODUÇÃO}

O Semiárido Brasileiro corresponde a $56,46 \%$ da região nordeste, além do norte de Minas Gerais. Parte do semiárido brasileiro é ocupado pelo bioma caatinga, caracterizado por ter um índice pluviométrico baixo, além de possuir grande diversidade de espécies vegetais, as quais apresentam mecanismos adaptativos para sobreviver a longos períodos de estiagem e temperaturas elevadas, sem perder em produtividade, como é o caso do umbuzeiro (CONTI et al., 2013).

A Spondias tuberosa, conhecida popularmente como umbuzeiro, pertence à família Anacardiaceae, é uma espécie nativa da caatinga. O umbuzeiro adapta-se perfeitamente a períodos prolongados de seca devido às raízes tuberosas que acumulam água e à queda de suas folhas, ele desenvolve-se naturalmente em regiões de clima quente, temperaturas entre $12^{\circ} \mathrm{C}$ e $38^{\circ} \mathrm{C}$, umidade relativa do ar entre 30 e $90 \%$ e 400 a $800 \mathrm{~mm}$ de chuva (entre novembro e fevereiro). Os frutos possuem importância econômica para as famílias do Nordeste, além de fazer parte da alimentação, complementam a renda geralmente gerada com o cultivo de culturas de sequeiro, como milho, feijão e mandioca, e a criação de caprinos e ovinos (BARRETO; CASTRO, 2010).

De grande importância social e econômica são as espécies florestais, assim como, as culturas agrícolas, e a manutenção de ambas dependem da implantação de sistemas agroflorestais e de projetos de recuperação de áreas degradadas que visem à otimização do uso da terra, conciliando a preservação das espécies arbóreas com a produção de alimentos, e assim, promover o desenvolvimento sustentável e a diminuição dos danos ao meio ambiente (FONTES et al., 2013). As espécies florestais endêmicas da região Nordeste podem ser exploradas de forma sustentável, quando fazem parte de um sistema agroflorestal, mas para isto deve-se verificar se há uma possível inibição da germinação de sementes e desenvolvimento inicial de plântulas de espécies cultivadas, para Loydi et al. (2015) a interação entre espécies pode ser desfavorável, quando uma afeta negativamente 0 
desenvolvimento da outra ao competir pelo mesmo recurso ou através da alelopatia. É de suma importância o conhecimento da atividade alelopática, pois possibilita o conhecimento das relações biológicas e químicas entre as espécies vegetais, auxiliando em técnicas que possam, dentre outros fatores, ser utilizadas na agricultura, como na implantação de agroflorestas e substituição ao uso de defensivos químicos (MALHEIROS et al., 2014).

As substâncias alelopáticas são resultantes do metabolismo secundário vegetal, em que se destacam substâncias fenólicas, terpenos e alcaloides (REIGOSA et al., 2013). A eliminação dessas substâncias para o meio ambiente pode se dar por diferentes formas, quais sejam: exsudação radicular, volatilização, lixiviação e decomposição de resíduos. Esses metabólicos liberados no meio podem afetar a germinação, o crescimento, a fisiologia e até mesmo os aspectos genéticos de plantas adjacentes (HARUN et al., 2014). Nos processos fisiológicos e bioquímicos os aleloquímicos podem interferir na utilização da água, na expansão foliar, na fotossíntese, no metabolismo dos aminoácidos e síntese protéica, na glicólise, na respiração mitocondrial e na síntese de ATP, entre outros (GUIDOTTI et al., 2013). A estimativa desse potencial pode ser realizada através de testes com espécies vegetais bioindicadoras, que são mais sensíveis à ação de metabólitos e que têm sido amplamente utilizadas em atividades laboratoriais, com baixo custo e alta eficiência, dentre as quais está a alface (KLEIN et al., 2014; ZORTÉA et al., 2015; MASUM et al., 2016).

Visto a importância em preservar as espécies nativas e as vantagens na adoção do sistema agroflorestal, é notória a necessidade de avaliação da capacidade alelopática das diversas espécies vegetais que possam ser adotadas nesse sistema, diante disso, o presente trabalho teve como objetivo avaliar o potencial alelopático de folhas secas em decomposição de umbu sobre 0 desenvolvimento inicial de feijão caupi (Vigna unguiculata L.).

\section{MATERIAL E MÉTODOS}

O experimento foi conduzido na Unidade Acadêmica de Serra Talhada/ Universidade Federal Rural de Pernambuco, durantes os meses de novembro de 2016 à janeiro de 2017. Foram utilizadas folhas secas da espécie nativa umbu (Spondias tuberosa Arr. Cam.) e a espécie cultivada observada quanto ao efeito alelopático foi feijão caupi.

As folhas da espécie florestal foram coletadas no período da manhã no município de Floresta - PE no mês de novembro, posteriormente secas a $60 \stackrel{\circ}{\mathrm{C}}$ por 24 horas em estufa, em seguida armazenadas em sacos de papel kraft, à temperatura ambiente até o momento de instalação dos experimentos. As folhas secas foram picadas manualmente e para confecção do substrato foram misturadas com areia, previamente esterilizada ( $200^{\circ} \mathrm{C}$ por duas horas), adotando-se a seguinte proporção para a mistura de areia e folhas secas: $1: 0 ; 1: 1 / 2 ; 1: 1$ e $1: 2$ (v:v). As folhas presentes em cada mistura ficaram decompondo por um período de zero; 15 ; 30; 45 e 60 dias, para posterior semeadura das sementes da espécie cultivada, utilizando bandejas de isopor de 128 células. A irrigação foi feita diariamente com água potável.

As avaliações foram realizadas diariamente após a semeadura, sendo avaliadas a porcentagem de emergência (PE), considerando as plântulas normais, índice de velocidade de emergência (IVE) conforme Maguire (1962) e tempo médio de emergência (TME) segundo Labouriau (1983). Posteriormente as plântulas normais de cada parcela foram utilizadas para avaliar o comprimento da parte aérea 
(CPA); comprimento do sistema radicular (CSR); massa seca da parte aérea (MSPA); massa seca do sistema radicular (MSR) e massa seca total (MST). A massa seca foi obtida através da secagem em estufa regulada a $80 \stackrel{\circ}{\circ}$ por 24 horas. Após a secagem se procedeu com a pesagem da parte aérea e do sistema radicular.

Para o experimento de decomposição de folhas secas, o delineamento utilizado foi o inteiramente casualizado em esquema fatorial $4 \times 5$, ou seja, quatro proporções de areia e folhas secas e cinco períodos de decomposição, com cinco repetições de 20 sementes por tratamento. As médias obtidas foram comparadas ao teste de Tukey a $5 \%$ de probabilidade utilizando o programa estatístico Assistat.

\section{RESULTADOS E DISCUSSÃO}

De acordo com a análise de variância, observou-se interação significativa para os períodos de decomposição e as proporções de areia e folhas secas de umbu para quase todas as variáveis analisadas, exceto para o tempo médio de emergência (Tabela 1).

TABELA 1. Resumo da análise de variância das médias dos parâmetros de avaliação sobre o desenvolvimento inicial de plântulas de feijão caupi (Vigna unguiculata L.) submetidas a diferentes proporções e períodos de decomposição de folhas secas de umbu (Spondias tuberosa).

\section{Quadrado Médio}

\begin{tabular}{|c|c|c|c|c|c|c|c|c|c|}
\hline \multirow{2}{*}{$\begin{array}{l}\text { Fonte de } \\
\text { variação }\end{array}$} & \multirow[b]{2}{*}{ GL } & & \multirow[b]{2}{*}{ MST } \\
\hline & & PE & TME & IVE & CPA & CSR & MSPA & MSSR & \\
\hline D & 4 & $\underset{*}{11,862^{*}}$ & $0,079^{\star *}$ & $0,044^{n}$ & $1,011^{*}$ & $0,881^{*}$ & $\underset{s}{0,028^{n}}$ & $0,016^{\text {ns }}$ & $\underset{\mathrm{ns}}{0,064}$ \\
\hline $\mathbf{P}$ & 3 & $\begin{array}{c}122,55 \\
4^{\star *}\end{array}$ & $1,309^{* *}$ & $0,015^{n}$ & $\underset{* *}{4,263}$ & $1,352^{*}$ & $\underset{* *}{0,493}$ & $0,032^{* *}$ & $\underset{* \star}{0,644}$ \\
\hline D x P & 12 & $4,116^{*}$ & $\underset{s}{0,0296^{n}}$ & $\underset{* *}{0,021}$ & $\underset{*}{0,499}$ & $0,685^{*}$ & $\underset{* *}{0,034}$ & $0,021^{* *}$ & $\underset{* *}{0,072}$ \\
\hline Tratamento & 19 & $\underset{*}{24,448^{*}}$ & $0,242^{* *}$ & $\underset{* *}{0,025}$ & 1,201 & $0,832^{* *}$ & $\underset{* *}{0,106}$ & $0,022^{* *}$ & $\underset{* *}{0,161}$ \\
\hline Resíduo & 80 & 2,081 & 0,018 & 0,156 & 0,263 & 0,344 & $\begin{array}{c}0,012 \\
8\end{array}$ & 0,007 & 0,026 \\
\hline CV (\%) & & $\dot{\delta}, 7$ & 10,11 & 23,69 & 10,0 & 22,34 & 9,62 & 7,75 & 12,8 \\
\hline
\end{tabular}

${ }^{\text {ns }},{ }^{* *},{ }^{*}$ respectivamente, não significativo e significativo a $1 \%$ e $5 \%$ de probabilidade pelo teste $\mathrm{F}$. Legenda: PE- Porcentagem de emergência (\%); TME - Tempo médio de emergência (dias); IVE Índice de velocidade de emergência; CPA - Comprimento da parte aérea $(\mathrm{cm})$; CSR - Comprimento do sistema radicular (cm); MSPA - Massa seca da parte aérea (g); MSSR - Massa seca do sistema radicular (g); MST - Massa seca total (g); D - Decomposição; P - Proporção.

Para a porcentagem de emergência, quando comparou-se os vários períodos de decomposição com as proporções de areia e folhas secas de umbu, observou-se que não houve diferença significativa entre os períodos de zero, 15, 30, 45 e 60 dias de decomposição com as proporções 1:0 e 1:2 (areia:folhas secas de umbu), já na proporção 1:1, 45 dias de decomposição foi o que resultou no pior resultado (Tabela 2), mas sem diferir dos períodos de 15 e 30 dias de decomposição, no período de 45 dias de decomposição houve maior liberação de substâncias alelopáticas para o meio em relação aos períodos de 15 e 30 dias, causando assim maior redução na emergência de plântulas de feijão caupi.

Quando analisadas as proporções de areia e folhas secas de umbu, de acordo com os vários períodos de decomposição, observou-se que na 
decomposição por zero, 15 e 60 dias a proporção 1:0 (apenas areia), foi a que resultou nos maiores porcentuais de emergência quando comparada as demais proporções. Já nos períodos de 30 e 45 dias de decomposição, com o aumento das proporções $(1: 1 ; 1: 1$ e 1:2) de folhas secas houve um efeito alelopático negativo, resultando em menor emergência. Em trabalho realizado por Carvalho et al. (2016) utilizando palhadas de guandu + milheto, feijão-de-porco + sorgo e crotalária + milheto, observaram que estas palhadas causaram maior redução na porcentagem de germinação de Brachiaria brizantha, descartando-se o efeito físico causado pela cobertura (vermiculita), pode-se inferir que substâncias exsudadas dessas palhas tenham afetado o processo germinativo.

Em análise histoquímica dos folíolos de Spondias tuberosa foi encontrada a presença de compostos fenólicos, taninos e alcalóides (SILVA et al., 2008), esses compostos podem interferir no balanço entre substâncias promotoras e inibidoras da germinação de sementes, assim como servirem de obstáculo à difusão de gases em sementes umedecidas.

TABELA 2. Interação dos diferentes períodos de decomposição com as proporções de folhas secas de umbu (Spondias tuberosa Arr. Cam), incorporadas à areia, sobre a porcentagem de emergência - PE e o índice de velocidade de emergência IVE, de plântulas de feijão caupi (Vigna unguiculata L.).

\begin{tabular}{|c|c|c|c|c|}
\hline \multicolumn{5}{|c|}{$\mathrm{PE}^{\#}(\%)$} \\
\hline \multirow[b]{2}{*}{$\begin{array}{c}\text { Decomposição } \\
\text { (dias) }\end{array}$} & \multicolumn{4}{|c|}{ Proporção (v/v) } \\
\hline & $1: 0$ & $1: 1 / 2$ & $1: 1$ & $1: 2$ \\
\hline 0 & $9,25 \mathrm{Aa}$ & $6,71 \mathrm{Ab}$ & $5,57 \mathrm{Ab}$ & $4,74 \mathrm{Ab}$ \\
\hline 15 & 8,71 $\mathrm{Aa}$ & 4,97 ABb & 2,64 BCb & $4,35 \mathrm{Ab}$ \\
\hline 30 & $8,40 \mathrm{Aa}$ & $2,76 \mathrm{Bb}$ & $3,82 \mathrm{ABCC}$ & $4,17 \mathrm{Ab}$ \\
\hline 45 & $8,42 \mathrm{Aa}$ & $4,67 \mathrm{ABb}$ & $1,89 \mathrm{Cc}$ & 3,95 Abc \\
\hline 60 & $8,58 \mathrm{Aa}$ & $4,12 \mathrm{Bb}$ & $4,91 \mathrm{ABb}$ & $5,43 \mathrm{Ab}$ \\
\hline CV(\%) & 26,70 & & & \\
\hline \multicolumn{5}{|c|}{ IVE $^{\#}$} \\
\hline & \multicolumn{4}{|c|}{ Proporção (v/v) } \\
\hline $\begin{array}{c}\text { Decomposição } \\
\text { (dias) }\end{array}$ & 1:0 & $1: 1 / 2$ & $1: 1$ & $1: 2$ \\
\hline 0 & $1,707 \mathrm{Aa}$ & $1,693 \mathrm{Aa}$ & 1,699 Aa & $1,721 \mathrm{Aa}$ \\
\hline 15 & $1,653 \mathrm{Aa}$ & 1,699 Aa & $1,840 \mathrm{Aa}$ & $1,709 \mathrm{Aa}$ \\
\hline 30 & $1,640 \mathrm{Aa}$ & $1,675 \mathrm{Aa}$ & $1,669 \mathrm{Aa}$ & $1,640 \mathrm{Aa}$ \\
\hline 45 & $1,728 \mathrm{Aa}$ & $1,6006 \mathrm{Aa}$ & $1,535 \mathrm{Aa}$ & $1,573 \mathrm{Aa}$ \\
\hline 60 & $1,662 \mathrm{Aa}$ & $1,604 \mathrm{Aa}$ & $1,740 \mathrm{Aa}$ & $1,565 \mathrm{Aa}$ \\
\hline $\mathrm{CV}(\%)$ & 23,69 & & & \\
\hline
\end{tabular}

Médias seguidas de mesma letra maiúscula na coluna e minúscula na linha, não diferem significativamente entre si, em nível de $5 \%$ de probabilidade. " Dados transformados utilizando $\sqrt{x}+1$

Já para o IVE não houve diferença entre as proporções de areia e folhas secas e os dias de decomposição (Tabela 2). A interação entre período de decomposição e proporções de folhas secas para o tempo médio de emergência não foi significativa (Tabela1), porém avaliando cada fator individualmente, observou-se que com relação aos períodos de decomposição, as plântulas provenientes das sementes semeadas apenas em areia (1:0/sem decomposição), demoraram mais AGRARIAN ACADEMY, Centro Científico Conhecer - Goiânia, v.4, n.8; p. 15 
dias para emergirem, apesar de não terem diferido das que emergiram no substrato, em que as folhas ficaram 60 dias se decompondo (Tabela 3).

Quando avaliadas as diferentes proporções de folhas secas de umbu, misturas com areia, verificou-se que a proporção 1:0 foi a que proporcionou pior resultado e que com o aumento da quantidade de folhas secas 1:1/1; 1:1 e 1:2 (areia:folhas secas) houve uma redução do TME, ou seja, as plântulas emergiram em menos dias. Muitas vezes, o efeito alelopático não se manifesta sobre a porcentagem de germinação, mas sobre a velocidade de germinação dos diásporos ou sobre outra característica do processo germinativo (FERREIRA ; AQUILA, 2000), sendo que nesse caso o efeito foi benéfico, uma vez que o aumento das proporções de areia:folhas secas propiciou menor tempo médio de emergência.

TABELA 3. Efeitos dos diferentes períodos de decomposição e diferentes proporções de folhas secas de umbu, incorporadas à areia, sobre o tempo médio de emergência - TME de plântulas de feijão caupi.

\begin{tabular}{lc}
\hline & TME" (dias) \\
\cline { 2 - 2 } Decomposição (dias) & \\
\hline $\mathbf{1 5}$ & $1,40750 \mathrm{a}$ \\
$\mathbf{3 0}$ & $1,282 \mathrm{~b}$ \\
$\mathbf{4 5}$ & $1,26550 \mathrm{~b}$ \\
$\mathbf{6 0}$ & $1,27650 \mathrm{~b}$ \\
Proporções (v/v) & $1,363 \mathrm{ab}$ \\
\hline $\mathbf{1 : 0}$ & \\
$\mathbf{1 : 1 / 2}$ & $1,6592 \mathrm{a}$ \\
$\mathbf{1 : 1}$ & $1,2292 \mathrm{~b}$ \\
$\mathbf{1 : 2}$ & $1,1632 \mathrm{~b}$ \\
\hline
\end{tabular}

Médias seguidas pela mesma letra minúscula nas colunas não diferem entre si pelo teste de Tukey ao nível de $5 \%$ de probabilidade. "Dados transformados utilizando $\sqrt{x}+1$

Quando avaliados os diferentes períodos de decomposição, observou-se que não houve diferença entre as quatro proporções de areia:folhas secas de umbu para o comprimento do sistema radicular; assim como para as proporções 1:1; 1:1/2 e 1:2 quanto ao comprimento da parte aérea (Tabela 4). Tanto o CPA como o CSR não foram afetados com o aumento das diferentes proporções de folhas secas de umbu quando estas ficaram por um período de 60 dias em decomposição, segundo Ferreira e Áquila (2000) a incorporação de restos de algumas culturas pode gerar funções alelopáticas devido aos compostos químicos liberados, sendo que em baixas quantidades pode haver uma disponibilização de nutrientes, porém quando maiores pode haver efeito alelopático. Quanto as folhas que não passaram por nenhum período de decomposição, houve uma redução da parte aérea, cujas médias variaram de 3,516 a $2,652 \mathrm{~cm}$. 
TABELA 4. Interação dos diferentes períodos de decomposição com as proporções de folhas secas de umbu (Spondias tuberosa Arr. Cam), incorporadas à areia, sobre o comprimento da parte aérea - CPA, comprimento do sistema radicular - CSR, massa seca da parte aérea - MSPA, massa seca do sistema radicular - MSSR e massa seca total - MST de plântulas de feijão caupi.

\begin{tabular}{|c|c|c|c|c|}
\hline \multirow[b]{3}{*}{ Decomposição (dias) } & \multicolumn{4}{|c|}{$\mathrm{CPA}^{\#}(\mathbf{c m})$} \\
\hline & \multicolumn{4}{|c|}{ Proporção (v/v) } \\
\hline & $1: 0$ & $1: 1 / 2$ & $1: 1$ & $1: 2$ \\
\hline 0 & $3,516 \mathrm{Aa}$ & 2,825 Aab & 2,685 ABab & $2,652 \mathrm{Ab}$ \\
\hline 15 & 3,315 Aa & 2,717 Aab & 1,872 Bb & $2,5998 \mathrm{Aab}$ \\
\hline 30 & $3,19 \mathrm{Aa}$ & 2,299 Ab & $2,1996 \mathrm{ABb}$ & 2,406 Aab \\
\hline 45 & 3,395 Aa & $2,998 \mathrm{Aa}$ & $1,815 \mathrm{Bb}$ & 2,269 Aa \\
\hline 60 & $3,127 \mathrm{Aa}$ & $3,121 \mathrm{Aa}$ & $2,916 \mathrm{Aa}$ & $3,140 \mathrm{Aa}$ \\
\hline \multirow[t]{3}{*}{$\mathrm{CV}(\%)$} & 18,30 & & & \\
\hline & \multicolumn{4}{|c|}{$\mathrm{CSR}^{\#}(\mathrm{~cm})$} \\
\hline & \multicolumn{4}{|c|}{ Proporção (v/v) } \\
\hline Decomposição (dias) & 1:0 & $1: 1 / 2$ & $1: 1$ & 1:2 \\
\hline 0 & $3,115 \mathrm{Aa}$ & $3,177 \mathrm{Aa}$ & $2,584 \mathrm{Aa}$ & $2,33 \mathrm{Aa}$ \\
\hline 15 & 2,991Aab & $2,835 \mathrm{Aab}$ & $2,045 \mathrm{Ab}$ & $3,062 \mathrm{Aa}$ \\
\hline 30 & $2,593 \mathrm{Aa}$ & $2,162 \mathrm{Aa}$ & $2,0796 \mathrm{Aa}$ & $2,249 \mathrm{Aa}$ \\
\hline 45 & $2,462 \mathrm{Aab}$ & $2,934 \mathrm{Aa}$ & $1,854 \mathrm{Ab}$ & $3,197 \mathrm{Aa}$ \\
\hline 60 & $2,454 \mathrm{Aa}$ & $2,7696 \mathrm{Aa}$ & 2,833 Aa & 2,799 Aa \\
\hline \multirow{3}{*}{$\mathrm{CV}(\%)$} & 22,34 & & & \\
\hline & \multicolumn{4}{|c|}{ MSPA $^{\#}(\mathbf{g})$} \\
\hline & \multicolumn{4}{|c|}{ Proporção (v/v) } \\
\hline Decomposição (dias) & $1: 0$ & $1: 1 / 2$ & $1: 1$ & $1: 2$ \\
\hline 0 & $1,4906 \mathrm{Aa}$ & $1,181 \mathrm{Ab}$ & $1,111 \mathrm{Ab}$ & $1,1472 \mathrm{ABb}$ \\
\hline 15 & $1,3916 \mathrm{ABa}$ & $1,0442 \mathrm{Ab}$ & $1,0126 \mathrm{Ab}$ & $1,118 \mathrm{Bb}$ \\
\hline 30 & $1,368 \mathrm{ABa}$ & $1,0278 \mathrm{Ab}$ & $1,047 \mathrm{Ab}$ & $1,1424 \mathrm{ABb}$ \\
\hline 45 & $1,43 \mathrm{Aa}$ & $1,0912 \mathrm{Ab}$ & $1,0566 \mathrm{Ab}$ & $1,0874 \mathrm{Bb}$ \\
\hline 60 & $1,2032 \mathrm{Bab}$ & 1,177 Aab & $1,0692 \mathrm{Ab}$ & $1,3206 \mathrm{Aa}$ \\
\hline \multirow[t]{3}{*}{$\mathrm{CV}(\%)$} & \multirow{2}{*}{\multicolumn{4}{|c|}{$\operatorname{MSSR}^{\#}(\mathrm{~g})$}} \\
\hline & & & & \\
\hline & \multicolumn{4}{|c|}{ Proporção (v/v) } \\
\hline Decomposição (dias) & $1: 0$ & $1: 1 / 2$ & $1: 1$ & $1: 2$ \\
\hline 0 & $1,168 \mathrm{ABab}$ & $1,247 \mathrm{Aa}$ & 1,1156 Aab & $1,0470 \mathrm{Ab}$ \\
\hline 15 & $1,176 \mathrm{ABa}$ & 1,053 Bab & $1,034 \mathrm{Ab}$ & $1,1568 \mathrm{Aab}$ \\
\hline 30 & $1,1172 \mathrm{ABa}$ & $1,0352 \mathrm{Ba}$ & $1,0568 \mathrm{Aa}$ & 1,0624 Aa \\
\hline 45 & 1,222 Aa & $1,0468 \mathrm{Bb}$ & $1,0318 \mathrm{Ab}$ & $1,0652 A b$ \\
\hline 60 & $1,064 \mathrm{Aa}$ & $1,0726 \mathrm{Ba}$ & $1,0828 \mathrm{Aa}$ & $1,157 \mathrm{Aa}$ \\
\hline \multirow[t]{3}{*}{$\mathrm{CV}(\%)$} & \multirow{2}{*}{\multicolumn{4}{|c|}{ MST $^{\#}(\mathbf{g})$}} \\
\hline & & & & \\
\hline & \multicolumn{4}{|c|}{ Proporção (v/v) } \\
\hline Decomposição & $1: 0$ & $1: 1 / 2$ & $1: 1$ & $1: 2$ \\
\hline 0 & $1.607 \mathrm{Aa}$ & $1,3912 \mathrm{Aab}$ & $1,213 \mathrm{Ab}$ & $1,186 \mathrm{ABb}$ \\
\hline 15 & $1,5244 \mathrm{ABa}$ & $1,0946 \mathrm{Bb}$ & $1,046 \mathrm{Ab}$ & $1,251 \mathrm{ABb}$ \\
\hline 30 & $1,452 \mathrm{ABa}$ & $1,0616 \mathrm{Bb}$ & $1,1004 \mathrm{Ab}$ & $1,195 \mathrm{ABab}$ \\
\hline 45 & $1,592 \mathrm{Aa}$ & $1,134 \mathrm{ABb}$ & $1,085 \mathrm{Ab}$ & $1,148 \mathrm{Bb}$ \\
\hline 60 & $1,2546 \mathrm{Bab}$ & $1,238 \mathrm{ABab}$ & $1,146 \mathrm{Ab}$ & $1,4414 \mathrm{Aa}$ \\
\hline
\end{tabular}

Médias seguidas de mesma letra maiúscula na coluna e minúscula na linha, não diferem significativamente entre si, em nível de $5 \%$ de probabilidade. "Dados transformados utilizando $\sqrt{x}+1$

AGRARIAN ACADEMY, Centro Científico Conhecer - Goiânia, v.4, n.8; p.17 2017 
De acordo com Ferreira e Áquila (2000) o crescimento da plântula é mais sensível aos aleloquímicos do que a germinação, pois o modo de ação direto dessas substâncias atua à partir da ligação nas membranas da planta receptora ou da penetração nas células, provocando interferência no metabolismo.

Houve uma redução da massa seca da parte aérea do feijão caupi quando foi utilizada apenas areia (1:0), correspondendo ao tratamento controle de 60 dias de decomposição das folhas secas, já com o aumento das proporções de folhas secas de umbu misturadas à areia houve um ganho em massa seca. Para Almeida (1988) as substâncias alelopáticas devem estar em concentrações mínimas no meio para atuarem sobre os organismos. Em altas concentrações pode haver disponibilidade de matéria orgânica rica em $\mathrm{N}$, essencial para o crescimento das culturas, e o caráter alelopático negativo pode ser suprimido. Isso pode explicar possíveis tendências de aumento em algumas variáveis analisadas quando a concentração foi mais elevada.

As massas secas da parte aérea e total foram afetadas com o aumento das proporções nos períodos de zero, 15, 30 e 45 dias de decomposição, quando comparadas às da proporção 1:0 (apenas areia), as quais apresentaram decréscimos nos seus valores. Essa redução provavelmente deve-se a ação inibitória dos compostos aleloquímicos presentes nas folhas de umbu, tais como os compostos fenólicos, taninos e alcalóides (SILVA et al., 2008).

Quanto a MSSR, ao avaliar os vários períodos de decomposição para cada proporção (Tabela 4), verificou-se que não houve diferença entre os períodos de decomposição para as proporções 1:1 e 1:2, já na proporção 1:1/2 a decomposição por zero dias propiciou melhores resultados em relação aos períodos de 15, 30, 45 e 60 dias de decomposição, nestes períodos houve uma maior liberação de substâncias alelopáticas para o meio quando comparados ao período de zero dias, contribuindo assim para reduzir a massa seca do sistema radicular.

\section{CONCLUSÕES}

O aumento das proporções de folhas secas de umbu reduziu a emergência das plântulas de feijão caupi, indicando uma interferência alelopática negativa, o mesmo ocorreu para os parâmetros relacionado ao desenvolvimento inicial das plântulas. Diante disso, conclui-se que não é recomendado o consórcio entre a espécie nativa Umbuzeiro com a espécie anual feijão caupi, visto que mesmo quando as folhas passaram por um período de decomposição continuaram afetando o desenvolvimento do feijão caupi.

\section{REFERÊNCIAS}

ALMEIDA, F. S. Alelopatia e as plantas. Londrina: IAPAR, 1988

BARRETO, L.S.; CASTRO, M.S. Boas práticas de manejo para o extrativismo sustentável do umbu. Brasília: Embrapa Recursos Genéticos e Biotecnologia, 2010

CARVALHO, W.P.; TEIXEIRA, L.G.V.; ABBADE NETO, D.O.; MOREIRA, J.M.S.; CUNHA, C.E. Alelopatia de resíduos de plantas de cobertura no controle de braquiária cv. Marandu. Revista brasileira de Biociências, v. 14, n.2, p. 60-69, 2016.

em:

<http://www.ufrgs.br/seerbio/ojs/index.php/rbb/article/view/2687> 
CONTI, I.L.; PONTEL, E.; SCHROEDER, E.O 2013. Transição paradigmática na convivência com o semiárido. In: Convivência com o Semiárido Brasileiro Autonomia e protagonismo social. Brasília: Editora IABS 29-38.

FERREIRA, A. G.; ÁQUILA, M. E. A. Alelopatia: uma área emergente da ecofisiologia. Revista Brasileira de Fisiologia Vegetal, Campinas, v. 12, p. 175204, 2000. Disponível em: <http://www.lpv.esalq.usp.br/sites/default/files/8\%20\%20Semana\%204\%20-\%20Alelopatia\%20na\%20agricultura\%20

$\% 20$ referencia\%20leitura\%20-\%20referencia\%20leitura.pdf>

FONTES, M. A.; RIBEIRO, G. T.; SIQUEIRA, E. R.; SIQUEIRA, P. Z. R.; RABANAL, J. E. M. Sistema agroflorestal sucessional como estilo produtivo para agricultura familiar em território de identidade rural, em Sergipe, Brasil. Revista Brasileira de Agroecologia, Pelotas-RS, v. 8, n. 2, p. 112-120, 2013. Disponível em: <http://www.aba-agroecologia.org.br/revistas/index.php/rbagroecologia/article/view/ $12854 / 8900>$.

GUIDOTTI, B.B.; GOMES, B.R.; SIQUEIRA-SOARES, R.C.; SOARES, A.R.; FERRARESE-FILHO, O. The effects of dopamine on root growth and enzyme activity in soybean seedlings. Plant Signaling \& Behavior. v. 8, n. 9, p. 1-7, 2013 Disponível em: <https://www.ncbi.nlm.nih.gov/pmc/articles/PMC4002588/>. DOI: $10.4161 /$ psb.25477

HARUN, M.A.Y.A.; JOHNSON, R.W.R.; UDDIN, M.Z. Allelopathic potential of Chrysanthemoides monilifera subsp. monilifera (boneseed): a novel weapon in the invasion processes. South African Journal of Botany, v.93, p.157-166, 2014. Disponível em: <http://www.sciencedirect.com/science/article/pii/S025462991400082 9 >. DOI: http://dx.doi.org/10.1016/j.sajb.2014.04.008

KLEIN, F. R. S.; MARTINAZZO, E. G.; PEDÓ, T.; AUMONDE, T. Z.; VILLELA, F. A. Performance de sementes e plântulas de alface sob ação alelopática de extratos de raízes de ginseng brasileiro. Tecnologia \& Ciência Agropecuária, v. 8, n. 5, p. 3943, $2014 . \quad$ Disponível em: <https://zeoserver.pb.gov.br/gestaounificada/gu/emepa/publicacoes/revistatcaemepa/ edicoes/volume-08-2014/volume-8-numero-5-dezembro-2014>.

LABOURIAU, L. G. A germinação das sementes. Washington: Secretaria Geral da Organização dos Estados Americanos, 1983. 174p.

LOYDI, A.; DONATH, T.W.; OTTE, A.; ECKSTEIN, R.L. Negative and positive interactions among plants: effects of competitors and litter on seedling emergence and growth of forest and grassland species. Plant Biology, v. 17, p.667-675, 2015. Disponível em: < http://onlinelibrary.wiley.com/doi/10.1111/plb.12287/pdf> DOI: 10.1111/plb.12287

MAGUIRE, J. D. Speed of germination aid in selection and evaluation for seedling emergence and vigor. Crop Science, Madison, v. 2, n. 2, p.176-77, 1962

MALHEIROS, R. S. P.; SANTANA, F. S.; LINHARES NETO, M. V. L.; MACHADO, L. L.; MAPELI, A. M. Atividade alelopática de extratos de Lafoensia pacari A. ST. -HIL. 
sobre Lactuca sativa L. e Zea mays L. em condições de laboratório. Revista Brasileira de Agroecologia, v. 9, n. 1, p. 185-194, 2014. Disponível em:<http://www.aba-agroecologia.org.br/revistas/index.php/rbagroecologia/article/ view/13439/9985>.

MASUM, S. M.; HOSSAIN, M. A.; AKAMINE, H.; SAKAGAMI. J.; BROWMIK, P. C. Allelopathic potential of indigenous Bangladeshi rice varieties. Weed Biology and Management. v. 16, n. 3, p. 119-131, 2016. Disponível em: <http://onlinelibrary.wiley.com/doi/10.1111/wbm.12103/abstracts. DOI: 10.1111/wbm.12103.

REIGOSA, M.; GOMES, A.S.; FERREIRA, A.G.; BORGHETTHI, F. Allelopathic research in Brazil. Acta Botanica Brasilica, v. 27, p. 629-646, 2013. Disponível em: < http://dx.doi.org/10.1590/S0102-33062013000400001>

SILVA, O.N.; CHINALIA, L. A.; PAIVA, J.G.A. Caracterização histoquímica dos folíolos de Spondias tuberosa ARRUDA (Anacardiaceae Lindl.). Caatinga, v.21, n.3, p.62-68, 2008. Disponível em: https://periodicos.ufersa.edu.br/index.php/caatinga/article/view/374/388>

ZORTÉA, K. É. M.; FREITAS JR, E.; SIMÃO. S. S.; SIMIONI, P. F.; ROSSI, A. A. B. Extratos de Alecrim são alelopáticos à germinação de Eruca sativa L.? Enciclopédia Biosfera, v. 11, n. 22, p. 3710-3718, 2015. Disponível em: <http://www.conhecer.org.br/enciclop/2015c/agrarias/EXTRATOS\%20DE\%20ALECR IM.pdf>. DOI: 10.18677/Enciclopedia_Biosfera_2015_258 